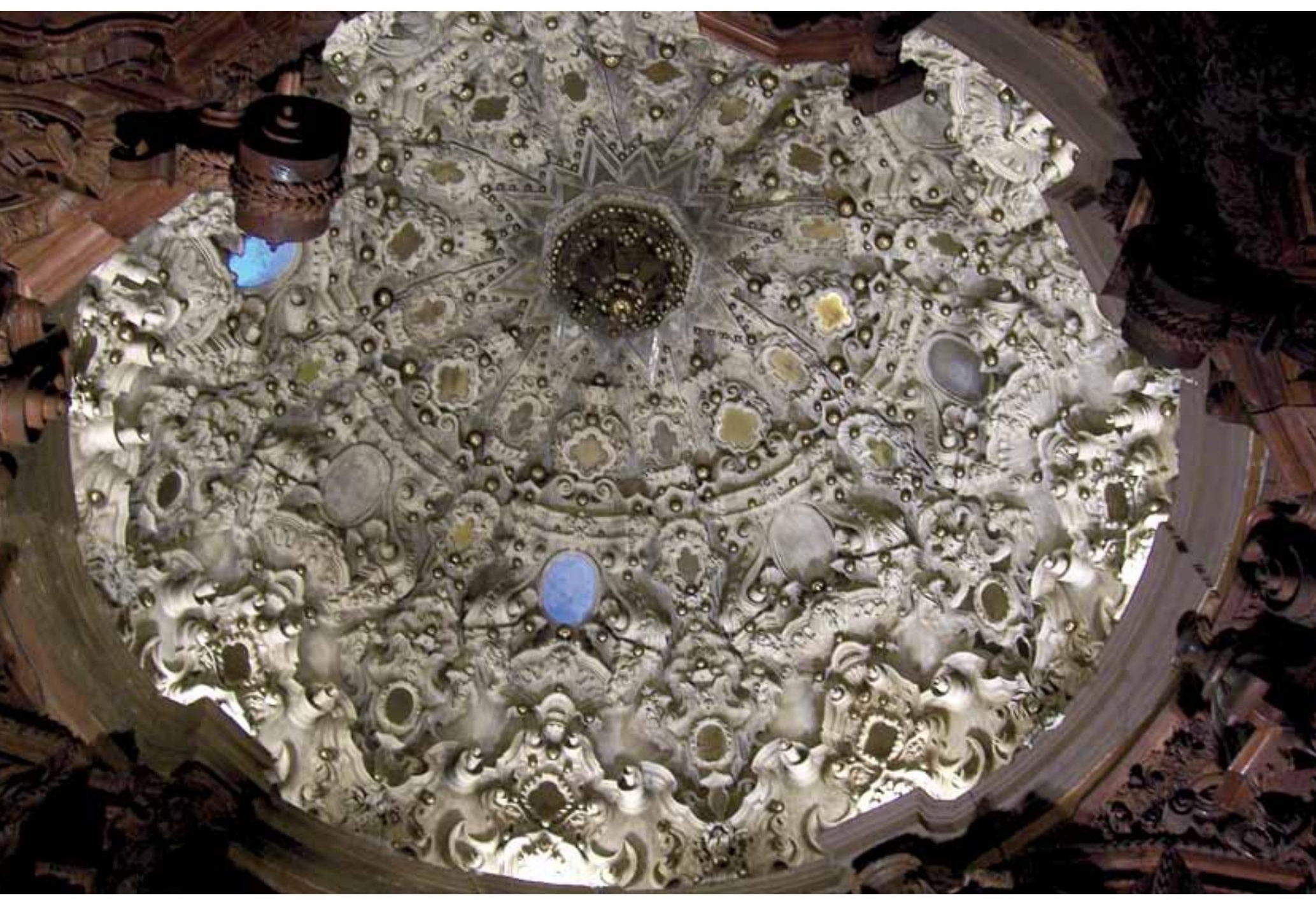

Cúpula del camarín de la Virgen de los Dolores de la iglesia de los Dolores, Baza. Foło: José Manuel Rodríguez Domingo 


\section{Patrimonio artístico mueble de las hoyas de Guadix y Baza}

José Manuel Rodríguez Domingo, U. de Granada y Centro de Estudios Pedro Suárez
La disposición geográfica de las hoyas de Guadix y Baza, situadas en la ruta natural que pone en comunicación el levante con la alta Andalucia, ha sido determinante en la configuración de una esencia histórica tan contrastada como su propio paisaje. Las extraordinarias capacidades físicas del territorio han modelado el carácter de los asentamientos que sobre él se sucedieron desde la Antigüedad hasta la conquista castellana, y con ello la variada calidad de su cultura material, objeto preferente de las disciplinas arqueológicas. No obstante, para el estudio de su patrimonio mueble de carácter artístico resulta esencial considerar esa actitud dual ante la realidad, habitualmente de apertura pero también de ocultamiento.

Enclavadas sobre un territorio árido, sometido a una climatología extrema, y con una evidente problemática social e ideológica, las comarcas del altiplano granadino no estuvieron Ilamadas a ser escenario privilegiado de los grandes desarrollos artísticos que caracterizaron otras áreas geográficas durante la Edad Moderna, quedando supeditadas al influjo de los poderosos focos granadino y murciano. Además, haciendo de la debilidad virtud, la vecindad con Jaén y la pertenencia de Huéscar al arzobispado de Toledo, lograron modelar un paisaje sincrético, dotado de personalidad propia y singular en su expresión plástica. Lamentablemente, si a este panorama sobreponemos las nefastas consecuencias provocadas por la invasión francesa, las desamortizaciones eclesiásticas y la Guerra Civil, obtenemos como resultado un legado tan ajustado como ignorado por la historiografía.

\section{EL PATRIMONIO CIVIL Y SEÑORIAL}

Del nuevo ordenamiento socio-político generado a partir de 1489 derivaron los desarrollos económicos y culturales que habian de converger en las ciudades -Guadix, Baza y Huéscar-, cuyo avituaIlamiento constituyó la principal actividad mercantil. Los procesos productivos quedaron así determinados por las necesidades del equipamiento edilicio, alli donde quedaba expresada mediante las figuras del corregidor y del municipio la capacidad del poder po- lítico de la Monarquia. Y al igual que para la Iglesia, las convulsiones politicas de distinta época también afectaron a su patrimonio mueble, centrado en los instrumentos de representación hegemónica, como aún permanece en las mazas barrocas de los cabildos oscense y bastetano. En contrapartida, las políticas culturales desarrolladas por algunos ayuntamientos en las últimas décadas están propiciando la conformación de colecciones, museos, centros de interpretación y fundaciones municipales -como los legados de Pedro Antonio de Alarcón y Julio Viconti, en Guadix- justificados en la defensa de la identidad local, ya por naturaleza individual, ya por su valor iconográfico.

De manera simultánea, el régimen señorial bajo el que se distribuyó el territorio auspició la presencia de una nueva nobleza, cuyo asentamiento quedó materialmente expresado a través de las manifestaciones externas del poder y la riqueza, hasta alcanzar en el castillo-palacio de La Calahorra su expresión culminante. De igual modo, se favoreció el vínculo temporal con los templos de su señorio, promoviendo a menudo su construcción, remodelación, adorno y equipamiento litúrgico. En la mayoría de los casos, tan sólo las heráldicas que campan en los arcos de ingreso a estas capillas evocan el esplendor que un día exhibieron; perviviendo, no obstante, modelos de gran significación patrimonial como las capillas de los Martínez Cañavate en Huéneja -con un rico programa pictórico mural- y de los Alvarado en la parroquial de La Calahorra, donde se despliega un sofisticado conjunto marmóreo importado de Génova.

Incluso, el coleccionismo privado alcanzó cierto desarrollo, tanto en su vertiente civil como eclesiástica, fomentado desde las diversas instancias asentadas en el territorio, tal es el caso de los marqueses de los Trujillos, de Lugros, de Villaalegre y de Diezma. Una muestra de esa extraordinaria elocuencia ideológica de las imágenes la hallamos en la pintura del Santo Cristo de Burgos, de la catedral de Guadix, réplica a su vez de la que quedó retenida en la localidad jiennense de Cabra cuando era trasladada por el corregidor Jerónimo de Sanvitores a su nuevo destino en 1636. En cualquier caso, y a tenor de las circuns- 

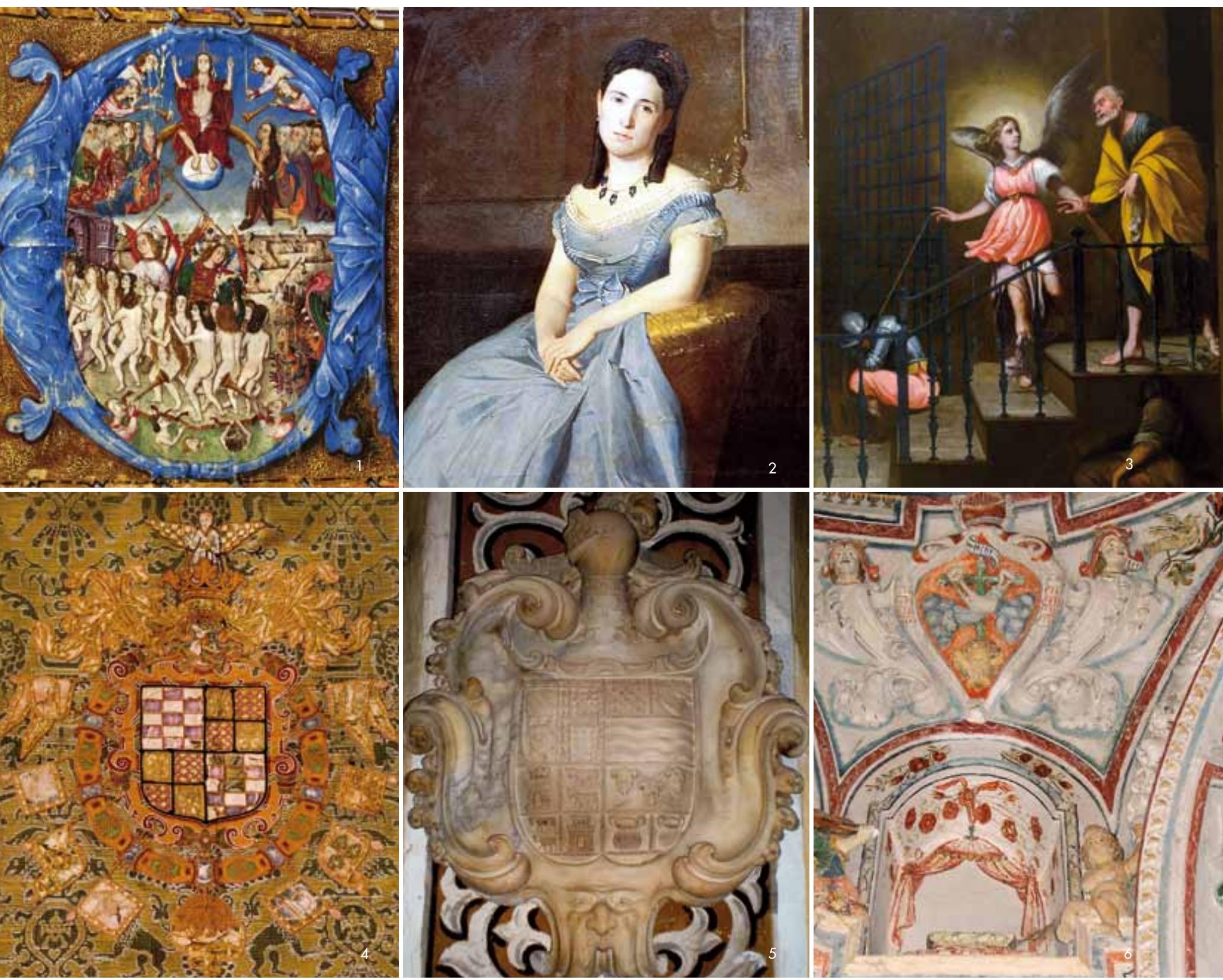

1. Juicio Final (c. 1500). Iglesia de la Anunciación, Baza. Foto: Francisco José Sánchez Montalbán

2. Dióscoro Puebla. Retrato de Paulina Contreras (1869). Sala Alarconiana Guadix. Foto: Torcuato Fandila García de los Reyes

3. Ambrosio de Valois. Liberación de San Pedro. Museo Catedralicio, Guadix. Foto: Francisco José Sánchez Montalbán

4. Escudo del II duque de Huéscar. Iglesia de Santa María la Mayor, Huéscar. Foto: Francisco José Sánchez Montalbán

5. Escudo de Juan Antonio Fernández de Alvarado. Iglesia de la Anunciación, La Calahorra. Foło: José Manuel Rodríguez Domingo

6. Capilla de la Virgen del Rosario. Iglesia de la Anunciación, Jérez del Marquesado. Foto: José Manuel Rodríguez Domingo tancias expresadas, se infiere cómo casi las únicas valoraciones que pueden establecerse en este campo quedan ligadas intimamente al ámbito eclesiástico, el único que pudo desarrollar una verdadera política de promoción y fomento artístico, ligado a su funcionalidad litúrgica y devocional, y transmitido -aunque parcialmente- hasta la actualidad.

\section{EL PATRIMONIO ECLESIÁSTICO}

Las circunstancias políticas que condujeron al establecimiento de una diócesis con sede en Guadix (1492), unido a la erección de iglesias parroquiales (1505), contribuyeron no sólo a la administración y evangelización de un territorio donde la presencia morisca era mayoritaria, sino a la implantación de un sistema de aculturación que encontró en el sistema constructivo mudéjar su 
aportación más significativa. La simplicidad material de las fábricas fue pareja a la modestia de su dotación mobiliar, limitada a los instrumentos de uso litúrgico, tal y como confirman los inventarios de la época. La destrucción ocasionada por el alzamiento morisco impidió su transmisión, excepción hecha de los establecimientos situados en los núcleos urbanos. Así, por su excelencia como piezas de representación, imágenes de culto o uso litúrgico que han llegado hasta nuestros dias, merecen señalarse el sepulcro del obispo fray García de Quijada (c. 1520) y la figura tardogótica de la llamada Virgen de la Cabeza, en Guadix; la imagen pétrea de la Virgen de la Piedad y el Ecce Homo atribuido a Luis de Morales, en Baza; o, en Huéscar, el portapaz vallisoletano de la Quinta Angustia y la espléndida custodia de asiento, "La TorreciIla", atribuida al platero jiennense Francisco Muñiz.

Cuando la segunda repoblación introdujo devociones vinculadas a la tradición de los nuevos habitantes, éstas intentaron ser contrarrestadas desde las instituciones diocesanas mediante el fomento de santos locales como San Torcuato, San Fandila o Santa Luparia, cuya nueva iconografía pronto se difundió mediante estampas, pinturas y esculturas. De otro lado, el crecimiento demográfico y el significativo aumento de hermandades determinaron la ampliación de los templos y la renovación del mobiliario litúrgico, gracias al aumento de la dotación económica procedente de diezmos y limosnas, a partir de la segunda mitad del siglo XVII. Así, el proceso decorativo alcanzó un extraordinario desarrollo, recubriéndose paramentos y bóvedas mediante ricas aplicaciones de yeso policromado y pinturas murales, especialmente en capillas y camarines; mientras que se intensificó la construcción de retablos, antes del traslado a Córdoba de los accitanos Juan y Pedro de Freila Ladrón de Guevara. Entre los ejemplos conservados de mayor antigüedad, sobresale el retablo de la Inmaculada Concepción, en la parroquial de la Puebla de Don Fadrique, deudor de los modelos de Gaspar Guerrero; así como el retablo de Nuestra Señora de la Presentación (1655-1657), en Huéneja, obra de Cecilio López, discípulo y cuñado de Alonso de Mena y suegro de Bernardo de Mora. Sin embargo, el hueco dejado por los obradores locales fue inmediatamente ocupado por talleres levantinos -Antonio Caro el Viejo, Mateo Sánchez Eslava o Pascual Alós-, quienes además se valieron de aprendices nativos que estaban llamados a convertirse en influyentes artífices, como Jerónimo Caballero, Juan de Uzeta, Gabriel Jiménez o Pedro Montoro.

De otro lado, la reactivación de las obras de la Catedral de Guadix, a partir de 1713, y la conclusión de su cabecera permitieron emprender iniciativas destinadas a la renovación mobiliar, siendo decisiva la munificencia corporativa de sus capitulares. Con ello asistimos a una recuperación de los talleres locales, encabezados ahora por Francisco Moreno, Salvador y José Guerrero, Damián de Casas, Jacinto Vergara o Cristóbal Rodríguez Mirantes. Esta intensa actividad -desarrollada entre 1734 y 1780 - contagió a otros templos de la comarca, como puede apreciarse en los retablos mayores de Albuñán y Beas de Guadix. Singular resulta, en este senti- do, la monumental máquina policromada de la iglesia de Cogollos de Guadix (1712-1718), obra de Antonio Martínez, cuyo interés se acrecienta por tratarse de la única pieza de características monumentales conservada en toda la diócesis.

La calidad que alcanzó la carpinteria litúrgica queda igualmente expresada en el conjunto de cajoneras, armarios, puertas y canceles realizados en el siglo XVIII. Destacan así, además del conjunto para la catedral accitana, el espléndido armario destinado en la iglesia de la Merced de Baza a contener un fabuloso ajuar de plata procedente de América. Sobresalen además las cajas de órgano, importantes elementos que prestigiaban la calidad sonora de estos instrumentos, como atestiguan los ejemplos conservados en Huéscar (1774) -obra del valenciano Matías Salanova-, Aldeire (1752) y Orce (1803). Pero, sin duda, los elementos más destacados vendrian conformados por las sillerias corales, de las que tan sólo se han conservado in situ las correspondientes a la iglesia de Santa María de Huéscar, obra de Jerónimo Caballero, y a la Catedral de Guadix, ejecutada por Pedro Fernández Pachote con imaginería -desaparecida- de Torcuato Ruiz del Peral, Valeriano Moyano, Cecilio Trujillo, Felipe González y Juan José Salazar. Por su parte, la difusión de la cantería cordobesa extendió el empleo de piedras y mármoles en el mobiliario litúrgico diocesano, destacando tanto los púlpitos catedralicios, como el labrado por Eusebio Valdés para la antigua colegial de Baza, dominado ya por el clasicismo académico. Bajo la nueva influencia estética cabe mencionar el tabernáculo y el trascoro de la Catedral de Guadix, así como el medallón de la Encarnación que centra su fachada principal.

Las artes plásticas en el territorio de las hoyas de Guadix y Baza desempeñaron un papel menor y subsidiario respecto de la retablistica, de ahí la reducida nómina de artistas establecidos permanentemente durante toda la Edad Moderna. No cabe duda que la proximidad con Granada y Jaén determinó su procedencia, como atestigua buena parte del legado pictórico conservado - procedente de donaciones de eclesiásticos y particulares-, en el que sobresalen obras atribuidas a Ambrosio Martínez de Bustos, Pedro Atanasio Bocanegra, Juan de Sevilla, José Risueño, Ambrosio de Valois o Gabriel Jiménez, entre otros. Similar resulta el panorama escultórico, aun cuando pueda constatarse un lógico interés por la talla policromada justificada en el auge de las devociones. Como en otros ámbitos de la vida social, la rivalidad entre las órdenes religiosas y las hermandades también estuvo dominada por la elocuencia expresiva de sus imágenes titulares. Todo lo cual justificaría el recurso a los artífices más destacados de la época, como los obradores granadinos de Alonso de Mena -Nuestra Señora de la Cabeza, en la iglesia de Castril-, José de Mora -Dolorosa de la Puebla de Don Fadrique- o Torcuato Ruiz del Peral -Virgen de la Humildad, del Museo Catedralicio-, todos con implicaciones familiares en el territorio; o procedentes del vecino Reino de Murcia, con encargos a Francisco Salzillo y Roque López, como el San Antonio Abad (1798) de la iglesia de Almaciles. 

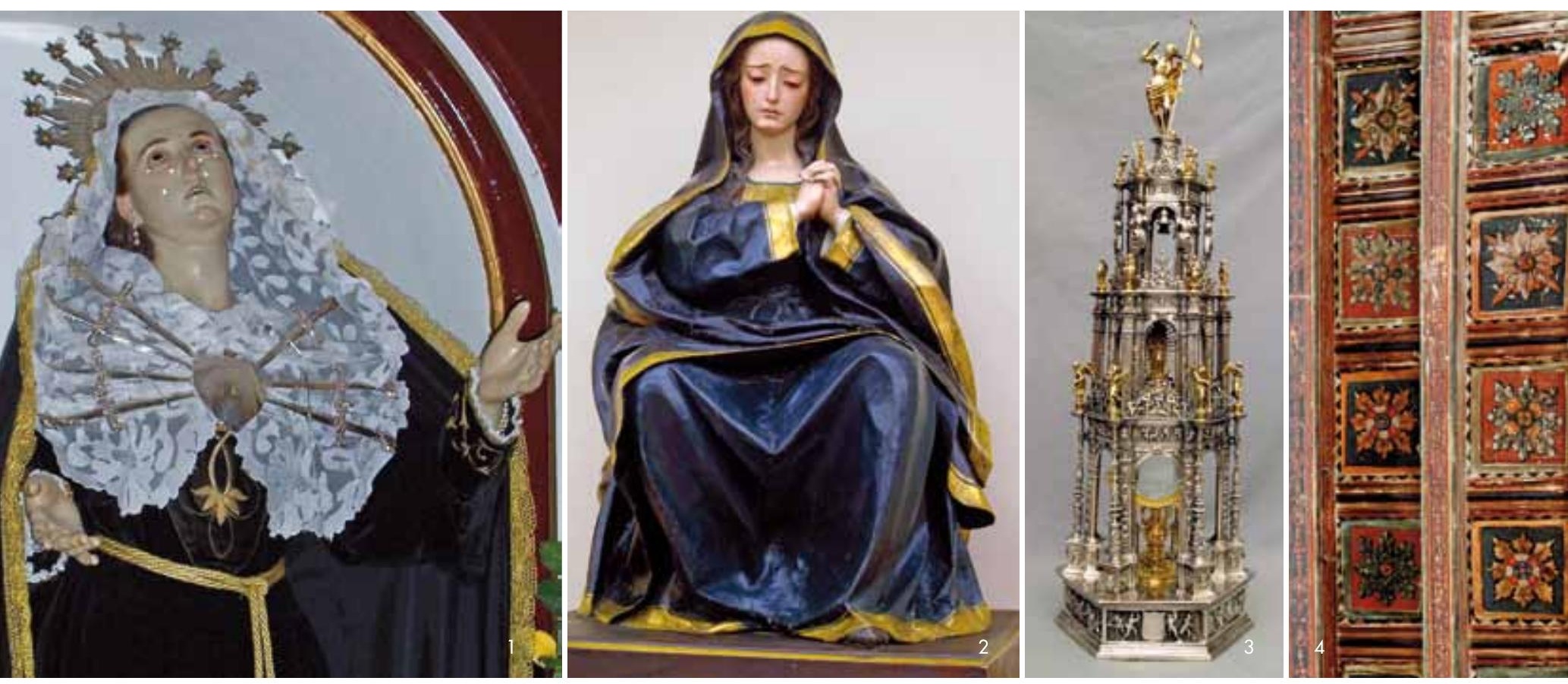

1. José Sánchez Lozano. Virgen de los Dolores. Iglesia de la Anunciación, Cúllar. Foto: José Manuel Rodríguez Domingo

2. Torcuato Ruiz del Peral. Virgen de la Humildad. Museo Catedralicio, Guadix. Foto: Francisco José Sánchez Montalbán
3. La Torrecilla. Iglesia de Santa María la Mayor, Huéscar. Foto: Francisco José Sánchez Montalbán

4. Detalle de alfarje policromado (s. XVI) de una vivienda señorial de Guadix. Foto: José Manuel Rodríguez Domingo
Respecto a las artes suntuarias, los valores materiales inherentes a las obras de orfebrería y la delicadeza de los textiles han condicionado una transmisión parcial y fragmentaria, compartiendo con el resto de actividades artísticas un hegemónico carácter sacro, y su dependencia de los obradores foráneos. Carentes estas comarcas de fiel contraste, hallamos un predominio de piezas granadinas y cordobesas, debidas a Damián de Castro, Bernabé García Aguilar, Antonio de Santa Cruz Zaldúa o Antonio Ruiz León. Entre las piezas conservadas de mayor interés sobresalen en Guadix el brazo-relicario de San Torcuato y los candeleros cincelados por Diego Cervantes, el Lignum Crucis de Huéscar, y las espléndidas piezas donadas por el abad Felipe Acuenza a la Colegiata de Baza. Por su parte, la paulatina decadencia del arte del bordado propició la importación de ornamentos tejidos en ricos materiales, fundamentalmente de talleres toledanos, como muestran los ternos de Orce, Baza, Huéscar y Guadix.

Finalmente, cabe considerar cómo frente a la perdurabilidad de la mayor parte de las fábricas eclesiásticas, su legado mobiliar ha sufrido en los últimos dos siglos una merma intensiva hasta reducirlo a una presencia testimonial. Los expolios y enajenaciones decimonónicas y, en especial, las nefastas consecuencias de la Guerra Civil sobre las comarcas de Guadix y Baza han conformado un desolado panorama artístico a pesar de los voluntariosos intentos por su reconstrucción. En cualquier caso, la refundación de hermandades y la reactivación de las devociones locales a partir de 1939 abrieron una etapa dorada para la imaginería que aún perdura. A pesar de su desigual resultado, no puede negarse la relevancia cultural y antropológi- ca de esta escultura contemporánea para las fiestas patronales y la celebración de la Semana Santa; desde el momento en que las tallas de los obradores andaluces y levantinos de José Sánchez Lozano, Antonio Castillo Lastrucci, José Navas Parejo, Amadeo Ruiz Olmos, Manuel Roldán de la Plata, Domingo Sánchez Mesa, Eduardo Espinosa Alfambra, José Manuel Bonilla, José Asenjo Fenoy o Israel Cornejo, han mantenido vigentes los exitosos tipos barrocos.

\section{EL INVENTARIO DE BIENES MUEBLES DE LA IGLESIA CATÓLICA EN LA DIÓCESIS DE GUADIX}

Aunque fuera en la diócesis de Granada donde se iniciara en 1989 el proceso de inventario de bienes muebles en la comunidad andaluza, el obispado de Guadix no se incorporó a este programa hasta el año 2004. Desde entonces, el equipo contratado por la Dirección General de Bienes Culturales de la Junta de Andalucia, dirigido por Ignacio Henares Cuéllar, catedrático de Historia del Arte de la Universidad de Granada, ha acometido el inventario del patrimonio mueble de los establecimientos eclesiásticos seleccionados por la Comisión Mixta, siguiendo para ello los criterios metodológicos propuestos por el IAPH. La singular coyuntura histórica de la diócesis ha condicionado el proceso de ejecución material de este trabajo, si bien a lo largo de las tres campañas desarrolladas -2004, 2007 y 2010se ha inventariado el patrimonio mobiliar de un total de dieciséis inmuebles, entre los que se incluyen la catedral de Guadix, las parroquias mayores de Baza y Huéscar, otros diez templos 
distribuidos en diferentes arciprestazgos, dos conventos y una ermita. La disponibilidad y extraordinario interés demostrado por los responsables diocesanos ha permitido acometer hasta el momento y sin apenas dificultades el inventario de 1.434 bienes, los cuales han sido incorporados a la correspondiente base de datos. Todo ello está aportando una información privilegiada acerca del verdadero carácter y estado de este desconocido patrimonio, actualizando toda la información relativa a su historia material con la incorporación de referencias documentales inéditas.

Coincidente con la puesta en marcha de este proyecto, en la última década se han propiciado importantes avances en las políticas de protección del patrimonio mobiliar de estas comarcas. Si bien la mayor parte de los templos diocesanos aún carecen de la correspondiente declaración como bienes de interés cultural, las intervenciones acometidas en estos años han desvelado aspectos constructivos y programas ornamentales hasta entonces ocultos. De otra parte, la puesta en funcionamiento de varios centros de interpretación y museos, como los municipales de Baza y Galera y el catedralicio de Guadix, proporcionan la dimensión cultural precisa que debe convertir este valioso acervo en sector estratégico para la configuración de su perfil territorial.

\section{Bibliografía}

AA.W. (2007) La Catedral de Guadix. Magna Splendore. Granada: Mouilaá Map, 2007

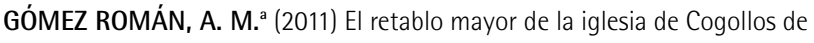
Guadix. Boletín del Centro de Estudios «Pedro Suárez», n. ${ }^{\circ} 24,2011$, pp. 89-98 GÓMEZ-MORENO CALERA, J. M. (1994-1995) Arquitectura y ornato en la altiplanicie granadina durante el siglo XVIII. Boletín del Instituto de Estudios "Pedro Suárez", n.os 7-8, 1994-1995, pp. 89-107

GÓMEZ-MORENO CALERA, J. M. (2009) Arquitectura mudéjar en la comarca de Guadix. Guadix: Centro de Iniciativas Turísticas, 2009 GÓMEZ-MORENO CALERA, J. M.; RODRÍGUEZ DOMINGO, J. M. (2010) Arquitectura y patrimonio religioso. En RUIZ PÉREZ, R. (dir.) Las huellas de la historia. El olvidado patrimonio del Marquesado del Cenete. Guadix: Padaya, 2010, pp. 247-310

LÓPEZ GUZMÁN, R. (2006) Guía artística de Granada y su provincia. Vol. II. Sevilla: Fundación José Manuel Lara, 2006

RODRíGUEZ DOMINGO, J. M. (1995) El patrimonio mueble de los conventos suprimidos por la desamortización de Mendizábal en Guadix (1835-1838).

Cuadernos de Arte de la Universidad de Granada, n. ${ }^{\circ} 26$, 1995, pp. 423-437 RODRíGUEZ DOMINGO, J. M. (2005) La serie de cobres flamencos del Obispado de Guadix. Cuadernos de Arte de la Universidad de Granada, n. ${ }^{\circ} 36,2005$, pp. 99-117

RODRÍGUEZ DOMINGO, J. M. (2007) El barroco en Guadix y el Altiplano. En AA.W. Andalucía Barroca: exposición itinerante. Sevilla: Consejería de Cultura, 2007, pp. 202-221

RODRÍGUEZ DOMINGO, J. M.; GÓMEZ ROMÁN, A. M. a (1999) El patrimonio artístico del Colegio de San Torcuato de Guadix, de la Compañía de Jesús. Boletín del Instituto de Estudios "Pedro Suárez», n. ${ }^{12}$, 1999, pp. 137-160

SEGADO BRAVO, P. (2008) Jerónimo Caballero. Retablista y escultor del Barroco (Huéscar 1668-Lorca 1751). Granada: Mouilaá Map, 2008

\section{En la web}

\section{ASOCIACIÓN PARA EL DESARROLLO RURAL DE LA COMARCA DE GUADIX}

www.comarcadeguadix.com

Organización dedicada a potenciar el desarrollo de la comarca de Guadix en sus múltiples ámbitos a través de proyectos y actividades. El sitio web ofrece información de los municipios que conforman la comarca a través de un acceso cartográfico.

\section{MUSEO DE GALERA}

Www.museodegalera.es

Organismo que se encarga de la conservación, investigación y difusión del patrimonio cultural de Galera. El sitio web del museo presenta secciones de arqueología y etnología así como información sobre los yacimientos de Castellón Alto y Tútugi.

\section{BLOG ARQUEOLOGÍA EN GALERA \\ http://arqueologiaengalera. \\ blogspot.com}

Blog sobre el patrimonio cultural de Galera. Noticias, enlaces de interés y documentos para descargar son algunos de los recursos que puede encontrar en este blog.

\section{PALEORAMA EN RED}

http://paleorama.wordpress.com

Blog sobre las últimas novedades en prehistoria y arqueología en el ámbito nacional e internacional. Presenta multitud de recursos: noticias organizadas por periodos, imágenes, publicaciones, ofertas de empleo y actividades de difusión entre otros.

\section{AYUNTAMIENTO DE ORCE}

\section{www.orce.es/es}

Web oficial del Ayuntamiento de Orce que ofrece información detallada del municipio así como de los elementos más destacados de su patrimonio cultural.

\section{FUNDACIÓN PATRIMONIO INDUSTRIAL DE ANDALUCÍA www.fupia.es}

Organización sin fines de lucro dedicada a la salvaguardia del patrimonio industrial de Andalucia. Podrá acceder a las intervenciones realizadas por la Fundación, noticias sobre patrimonio industrial, enlaces de interés y acceso a las conclusiones de las I Jornadas Andaluzas de Patrimonio Industrial y Obra Pública celebradas en 2010.

\section{INSTITUTO GEOLÓGICO MINERO DE ESPAÑA}

www.igme.es

Organismo público de investigación que presenta entre sus líneas de acción la producción de cartografía geocientífica, análisis de los recursos minerales e impacto ambiental de la minería, patrimonio geológico minero y cultura científica entre otras. Entre los productos que ofrece este organismo en su web se encuentran Panorama minero y una gran variedad de bases de datos como Patrigeo, con información de los puntos de interés geológico.
MEGALITOS DE ESPAÑA. AMIGOS DO AROUEOLÓXICO A CORUÑA

http://megalitos.arqueoloxico.com

Sitio web que presenta información detallada de los megalitos de España a través de un acceso geográfico. Datos de identificación, accesos y señalización, imágenes, planos y alzados, y bibliografia son los recursos que podrá encontrar en esta web.

\section{CENTRO DE ESTUDIOS PEDRO SUÁREZ}

www.diocesisdeguadixbaza.org/2/ index.php/instituciones/centroestudios-qpedro-suarezq.html

Asociación integrada por estudiosos e investigadores cuya finalidad principal es colaborar en la investigación, conservación y difusión del patrimonio cultural del territorio que comprende la Diócesis de Guadix-Baza (Granada), propiciando y fomentando el desarroIlo científico, cultural, social y económico de las comarcas de Guadix, Baza y Huéscar. 